\title{
Attendance of general practitioners at child protection case conferences
}

\author{
Caroline Lea-Cox, Alyson Hall
}

TABLE I - Most important reason for general practitioners not attending child protection case conferences

\begin{tabular}{lc}
\hline Reason & $\begin{array}{c}\text { No of } \\
\text { doctors } \\
(\mathbf{n}=\mathbf{4 7})^{\star}\end{array}$ \\
\hline Timing of conference & 35 \\
Notice too short & 13 \\
Not informed of conference & 6 \\
No role for general & \\
practitioner & 4 \\
Inconvenient location & 2 \\
\hline ॠNine doctors ranked two or more \\
reasons as equally important.
\end{tabular}

Chrisp Street Health
Centre, London E14 6PG
Caroline Lea-Cox, MRCGP,
general practitioner

Emanuel Miller Centre for

Families and Children,

London E14 8HG

Alyson Hall, MRCPSYCH, consultant child and adolescent psychiatrist

Correspondence to:

Dr Lea-Cox.

BMF 1991;302:1378-9

\section{Abstract}

Objective-To investigate general practitioners' attendance at and views on child protection conferences and their confidence in dealing with sexual abuse in children.

Design-Anonymous postal questionnaire sent to all general practitioners in Tower Hamlets and review of consecutive case conferences held by social services for three months in 1989.

Setting-Tower Hamlets health district.

Subjects-91 general practitioners, 56 of whom $(62 \%)$ responded.

Main outcome measures-Number of conferences attended, reasons for non-attendance, and reported confidence in dealing with sexual abuse.

Results-General practitioners estimated that 202 child protection conferences had been held in 1989 on their patients and that they had attended 85 of these. Information from social services for three months suggested that general practitioners had attended only nine of the $\mathbf{1 1 4}$ conferences reviewed. Timing of the conference was the most important reason for non-attendance. All respondents wanted access to the minutes of these conferences irrespective of their own attendance. Most general practitioners were very or moderately confident of their ability to detect child sexual abuse and nonaccidental injury and to communicate with the family.

Conclusion-More effort should be made to ensure that general practitioners are notified of case conferences and that the timing and location of conferences is compatible with their other commitments.

\section{Introduction}

Protection of children from abuse is attracting increasing attention in both the media and the medical press. ${ }^{12}$ In Tower Hamlets, a small, socially deprived district in east London, the prevalence of child abuse has always been high, but the number of investigations has recently increased noticeably. ${ }^{3}$ Tower Hamlets has a high birth rate and thus a disproportionately large population of children aged under $16(50000))^{34}$ The increase in child protection work may be due to increasing incidence or to growing professional awareness and detection.

Social workers and other professionals working in child protection expressed concern to the area child protection committee about the limited participation of general practitioners, particularly their infrequent attendance at child protection conferences. ${ }^{3}$ General practitioners have an important role in developing a therapeutic relationship between the family and other professionals and can provide support when social services are seen as hostile or threatening. ${ }^{56} \mathrm{We}$ conducted a survey of general practitioners to deter- mine the reason for their low attendance at these conferences.

\section{Subjects and methods}

We sent a postal questionnaire and explanatory letter to all the general practitioners in Tower Hamlets. The mailing was repeated one month later to maximise response. The questionnaire was anonymous and asked about the number of child protection conferences attended in the past year, the reasons for non-attendance, views on receiving minutes of case conferences, concerns regarding confidentiality of these minutes, and confidence in diagnostic ability and in communication with families of abused children. General practitioners were asked whom they would contact first to discuss a suspected case of child sexual abuse and whether there was any training that would be helpful.

To calculate the actual attendance of general practitioners at initial and follow up child protection conferences in 1989, we reviewed the minutes of consecutive case conferences from social services and the youth and community section of the police for three months in 1989.

\section{Results}

We received completed questionnaires from 56 of the 91 general practitioners in Tower Hamlets $(62 \%)$. There were 193 initial case conferences in Tower Hamlets in 1989, of which 83 were about child sexual abuse cases; 90 concerned other forms of child abuse and 20 general care and neglect. There were also 550 review conferences. We reviewed the minutes of 114 conferencès, 57 of which were initial case conferences. General practitioners attended nine of the 114 conferences (six initial case conferences) in the three months and sent apologies for non-attendance for 15 conferences (12 initial conferences).

The 56 responding general practitioners estimated that a total of 202 child protection conferences had been held on their patients in 1989. They estimated that they had attended 85 of these conferences (mean (range) $3 \cdot 5(0-20)$ conferences/general practitioner per year). Information from social services suggested that there was an average of eight child protection conferences per general practitioner in 1989. However, the general practitioners said they would have liked to have attended more conferences.

We asked general practitioners to rank in order of importance a list of suggested reasons why they had not been able to attend the case conferences. Table I shows the most important reasons. Forty seven general practitioners responded to this section, and nine rated two or more reasons as equally important. Other reasons for non-attendance included poor chairmanship and conferences that were too frequent or too 
TABLE II - Person general practitioners would first contact in suspected cases of child sexual abuse detected in surgery

\begin{tabular}{lcc}
\hline & \multicolumn{2}{c}{ No of doctors $(\mathbf{n}=56)$} \\
\cline { 2 - 3 } & $\begin{array}{c}\text { Morning } \\
\text { surgery }\end{array}$ & $\begin{array}{c}\text { Evening } \\
\text { surgery }\end{array}$ \\
\hline $\begin{array}{c}\text { Health } \\
\text { visitor }\end{array}$ & 23 & 5 \\
$\begin{array}{c}\text { Paediatric } \\
\text { consultant }\end{array}$ & 11 & 7 \\
$\begin{array}{c}\text { Paediatric } \\
\text { registrar }\end{array}$ & 11 & 30 \\
$\begin{array}{c}\text { Social } \\
\text { worker }\end{array}$ & 6 & 10 \\
\begin{tabular}{c} 
Other \\
\hline
\end{tabular} & 5 & 4 \\
\hline
\end{tabular}

long. Many conferences competed with general practitioners' other commitments and several suggested that they could adequately provide input by a written or telephone report. Doctors also mentioned difficulties with claiming fees for attendance at conferences, especially where locum expenses were incurred.

All the general practitioners who replied thought that they should be sent the minutes of the conferences irrespective of whether they had been able to attend. Fifteen of the 56 general practitioners had some concern about maintaining confidentiality of these minutes in the practice, and 36 thought that other members of staff, including receptionists and health visitors, would have access to these minutes.

Table II shows the person who general practitioners would first contact to discuss a case of suspected child sexual abuse identified in routine surgery. The health visitor was the most likely contact in morning surgery, but for cases detected in evening surgery the paediatric registrar was more likely to be contacted.

Most general practitioners were very or moderately confident in their ability to detect child sexual abuse (35/56) and non-accidental injury (52/56) and to communicate with the family when child abuse had been discovered (42/56). Nevertheless, 20 general practitioners said that they were not at all confident in diagnosing child sexual abuse and 12 that they were not confident in communicating with the family. General practitioners' suggestions for improvement in managing sexual abuse were training in practical skills in diagnosing child sexual abuse, especially anal abuse; training in normal genital development; increased training in child psychiatry for counselling and communication skills; regular meetings with child health services; regular study half days to discuss cases; annual update of procedures; and more locally based training. Twenty four did not specify any improvements or training.

\section{Discussion}

Our study suggests that general practitioners attend child protection conferences infrequently. The questionnaire was anonymous so we could not differentiate between the responders and non-responders. Respondents may have attended more child protection conferences than non-responders, which could account for some of the discrepancy between information obtained from the general practitioners and that from social services.

General practitioners were more likely to attend or give apologies for an initial conference, but it is unclear whether greater efforts were made to invite them to these. The discrepancy between the information from social services and the general practitioners suggests that the general practitioners were not informed about or invited to attend the conferences. Social workers are often unaware of the name of the general practitioner, and some families may not have been registered with a general practitioner or may have been registered under a different name. In Tower Hamlets, invitations to attend child protection conferences are usually sent to individual general practitioners rather than to a group practice, where it may be unclear who should take responsibility.

A few general practitioners did not want to attend child protection conferences. For those wishing to attend, the timing of the conference was the most important reason for non-attendance. It has been recommended that case conferences should be arranged so that those with inflexible commitments can attend. ${ }^{7}$ This would be particularly important for single handed practitioners. Location of conferences in general practitioners' surgeries has recently been encouraged, and this may circumvent some of the problems such as shortage of notice and timing of the conference.

Those who are invited to a case conference but are unable to attend should ensure that their contribution is made through a written note to the chairperson. Several general practitioners suggested that a verbal or written report may be more appropriate than attendance. Difficulties have arisen with claiming fees from the district health authority, mainly because no standardised procedures or claim forms exist. This raises the question whether the health authority's budget would meet the cost if general practitioners attended all case conferences.

All the general practitioners questioned wanted minutes of the child protection conferences on their patients irrespective of their attendance. Often this would be the only way for them to ascertain if the child has been placed on the child protection register. As the minutes should include the date of the review conference this could facilitate general practitioners' attendance at later conferences.

Despite the existing child protection procedures in Tower Hamlets there was wide variation among general practitioners about who they would contact first to discuss a case of child sexual abuse. Often a junior member of the hospital paediatric team was contacted in preference to a member of the child protection team as recommended in local procedures. We do not know whether the general practitioners have poor access to the procedures, whether they are unaware of the contents, whether the procedures are unclear, or whether the relevant members of the child protection team are difficult to contact, particularly in evening surgery.

Forty three per cent of doctors did not specify any training that would be helpful to them. It would be interesting to compare this response with that of general practitioners in areas with a lower prevalence of child abuse.

We have made the following recommendations to the area child protection committee to increase general practitioners' attendance at child protection conferences. Firstly, the social worker should ascertain the general practitioner in each case and inform him or her that the conference is being held. Secondly, greater consideration should be given to the timing and location of the conference, and verbal or written reports should be made available to the chairperson if a general practitioner is unable to attend. Thirdly, general practitioners should receive the minutes of all child protection conferences on their patients. Finally, the process of claiming fees for attendance at child protection conferences should be clarified.

We thank Brenda Dibble, administrative assistant for child protection, and Jean Gabbott, child protection coordinator for Tower Hamlets, for help with collecting data. We thank all the general practitioners who responded to the questionnaire and Hermione Murrell for typing the manuscript.

1 Meadow R, ed. $A B C$ of child abuse. London: BMJ, 1989

2 Butler-Sloss E. Report of the inquiry into child abuse in Cleveland, 1987 London: HMSO, 1988. (Cm 412.)

Department of Community Medicine and Public Health, Tower Hamlets Health Authority. Tower Hamlets people health report No 1. London: Tower Hamlets Health Authority, 1988

4 Department of Community Medicine and Public Health, Tower Hamlets Health Authority. Tower Hamlets people health report No 2. London: Tower Hamlets Health Aus Hamles 0

5 Hall A. Teamwork vital in suspected cases of abuse. Hospital Doctor 1989;22:28.

6 Hall A Harris RJ. The development of a multidisciplinary approach to the assessment and management of child sexual abuse in an inner city health district. Health Trends 1988;20:39-43.

7 Department of Health and Social Security and the Welsh Office. Working together. A guide to arrangements for inter-agency cooperation for the protection of children from abuse. London: HMSO, 1988.

(Accepted 17 April 1991) 